\title{
Indoleamine-2,3-dioxygenase and Interleukin-6 associated with tumor response to neoadjuvant chemotherapy in breast cancer
}

\author{
Fangxuan Li ${ }^{1, *}$, Lijuan Wei ${ }^{1, *}$, Shixia $\mathbf{L i}^{1}$ and Juntian Liu ${ }^{1}$ \\ ${ }^{1}$ Department of Cancer Prevention, Tianjin Medical University Cancer Institute and Hospital, National Clinical Research \\ Center for Cancer, Tianjin's Clinical Research Center for Cancer, Key Laboratory of Cancer Prevention and Therapy, Tianjin \\ 300060, China \\ *These authors have contributed equally to this work \\ Correspondence to: Fangxuan Li, email: lifangxuan2008@126.com \\ Juntian Liv, email: ljt641024@163.com \\ Keywords: Indoleamine-2,3-dioxygenase; Interleukin-6; neoadjuvant chemotherapy; breast cancer; clinical response \\ Received: June 13,2017 Accepted: October 02, $2017 \quad$ Published: November 01, 2017 \\ Copyright: Li et al. This is an open-access article distributed under the terms of the Creative Commons Attribution License \\ 3.0 (CC BY 3.0), which permits unrestricted use, distribution, and reproduction in any medium, provided the original author and \\ source are credited.
}

\section{ABSTRACT}

Purpose: Indoleamine-2,3-dioxygenase (IDO) and Interleukin-6 (IL-6) contribute to poor therapeutic effects, tumor relapse and aggressive tumor growth. IDO and IL-6 incorporate a positive feedback signal loop to maintain IDO and IL-6 constitutive expression and facilitate tumor progression.

Results: IDO expression was associated with IL-6 expression and plasma IL-6 level $(P<0.05)$. Concentrating on clinicopathological features prior neoadjuvant chemotherapy, both IDO expression and plasma IL-6 level were associated with clinical $\mathrm{T}$ stage and $\mathbf{N}$ stage $(P<0.05)$. IL-6 expression was associated with clinical T stage $(P=0.016)$. The co-expression of IDO/IL-6 was correlated with clinical $T, N$ stage and estrogen receptor $(E R)$ status $(P<0.05)$. IDO, IL-6 expression, clinical T stage, pathological T stage, ER status and Luminal type were correlated with clinical response to neoadjuvant chemotherapy $(P<0.05)$. Multivariate analysis showed that IDO expression were correlated with clinical response to neoadjuvant chemotherapy $(P=0.034)$. IL-6 expression and pathological $T$ stage were correlated with $\mathrm{PCR}$ $(P<0.05)$. In the multivariate analysis, postoperative pathological $\mathrm{T}$ stage associated with PCR $(P=0.041)$. In the prognostic analysis, only clinical $T$ stage was significant correlated with overall survival $(P=0.003)$.

Materials and Methods: 46 breast cancer patients received neoadjuvant chemotherapy enrolled in this study. Immunohistochemistry was applied for evaluating IDO and IL-6 expression in biopsy tissues prior neoadjuvant chemotherapy. Immunofluorescence was applied to observe the co-localization of IDO and IL-6. Serum IL-6 level was examined via ELISA. The associations between IDO, IL-6, Serum IL-6 level and clinicopathological features, response to neoadjuvant chemotherapy were analyzed.

Conclusion: IDO and IL-6 expression associated with advanced breast cancer and poor response to neoadjuvant chemotherapy.

\section{INTRODUCTION}

Worldwide, breast cancer is the most common malignant tumor in female [1]. Chemotherapy is predominantly used for breast cancer at stages II to stage
IV, and is particularly beneficial for estrogen receptor negative (ER-) patients [2]. Neoadjuvant chemotherapy is a recent treatment regimen for breast cancer patients who were diagnosed with high risk non-metastatic breast cancer including locally advanced and inflammatory 
breast cancer. This approach was reported to shrink the tumor prior to mastectomy or lumpectomy [3], which can improve breast conserving rates, decrease the recurrence, prolong progression free survival (PFS) and overall survival (OS). What's more, in neoadjuvant chemotherapy, tumor size reduction and treatment tolerability could be evaluated, with potential for modifying chemotherapy regimens to increase rates of pathological complete response (pCR), which allowed the primary tumor response to serve as a mean of chemo-sensitivity estimation [4]. pCR is reported to be a useful prognostic marker, since patients who achieve pCR exhibit significant improvement in survival $[5,6]$.

The important role of the immune system in tumor occurrence and progression has been debated for many years. Swann et al had demonstrated malignant cells can escape the immunology surveillance via various ways. One of these important ways is immune suppression, which could depend on many tumor and host factors, involving different inflammatory molecules [7].

Interleukin-6 (IL-6) is one such inflammatory molecule. It is involved in the proliferation and differentiation of tumor cells and demonstrated to be high in serum and tumor tissues in series cancers, eg. colorectal cancer, breast cancer, prostate cancer [8]. It had confirmed that IL-6 contributes to poor therapeutic effect, tumor recurrence and aggressive tumor growth. In previous study, patients with higher serum IL-6 are generally associated with poorer prognosis, while lower level IL-6 is associated with better response to therapy [9]. It implies that malignant cells secret IL-6 as a protective mechanism against chemotherapy induced cell death $[10,11]$. Series studies found that high level IL-6 cause resistance via mediating STAT3 activation [12] and inducing expression of the multidrug resistance gene and CYP450 enzymes through the janus kinase/signal transducers and activators of transcription (JAK/STAT) and phosphatidylinositol 3 kinase/protein kinase B (PI3K/AKT) pathways [13].

Indoleamine-2,3-dioxygenase (IDO) acts in tumor, stromal and immune cells to promote pathogenic inflammatory reaction which induce the immune escape of tumor cells [14, 15]. Muller et al. reported that IDO inhibition combined with chemotherapeutic drugs to effectively promote the suppressor of recurrent breast neoplasm [16]. In Okamoto et al's study, greater expression of IDO was confirmed not only in tumors from chemoresistant patients but also in chemoresistant ovarian cancer cell lines, suggesting that IDO may participate in chemosensitivity by intracellular mechanisms [17]. In glioblastoma's study, the IDO pathway contribute to complement dependent enhancement of chemo-radiation treatment for murine glioblastoma (GL261 tumors in syngeneic host mice) [18].

IDO was demonstrated to drive IL-6 production in lung cancer and metastatic breast cancer, while, downstream product of IDO metabolism, kynurenic acid, can potentiate IL-6 production by the aryl hydrocarbon receptor (AHR) [19]. Yet, IL-6 was reported, in turn to induce IDO expression through JAK/STAT signaling in rat hippocampus (Wistar rat, C57BL/6J wild type mice and

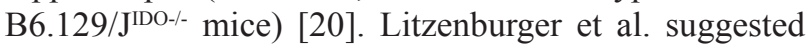
that IDO-AHR-IL-6-STAT3 positive feedback signal loop maintain IDO and IL-6 expression in human cancer cells which may imply novel targets of this pathway promoting immunosuppression for cancer treatment [21].

Thus, in our study we evaluated the IDO and IL-6 expression of biopsy specimens and IL-6 level of serum collected prior to neoadjuvant chemotherapy based on clinical and pathological response to chemotherapy, to explore the association between IDO, IL-6 expression and clinicopathological features, response to neoadjuvant chemotherapy and prognosis of breast cancer patients.

\section{RESULTS}

\section{The association between IDO, IL-6 expression and plasma IL-6 level}

The Figure 1A showed the expression of IDO and IL-6 in tumor tissues. Figure 1B showed that the patients with high IDO expression more frequently had higher IL-6 high expression. From the total of 46 patients, 26 patients were high expression of IDO, 27 patients were high for IL-6 expression, and 19 patients were positive for both IDO and IL-6 expression. In Figure 1C, it was found that the sum score of IDO correlated with the sum score of IL-6 $\left(r^{2}=0.655, P<0.001\right)$ by Spearman's rank correlation test. Figure 1D showed that the level of plasma IL-6 in patients with high IDO expression $(7.183 \pm 3.678 \mathrm{pg} / \mathrm{mL}$, Range: $2.510 \sim 16.021 \mathrm{pg} / \mathrm{mL})$ was higher than patients with low IDO expression $(4.030 \pm 1.713 \mathrm{pg} / \mathrm{mL}$, Range: $1.495 \sim 7.487 \mathrm{pg} / \mathrm{mL}, t=3.487, P=0.001)$. The IDO and IL-6 expression status in breast cancer tissues were assessed by immunofluorescence double staining as shown in Figure $1 \mathrm{E}$. In the present study, the two-mixed primary antibody set were used and the images were visualized using two colors as green (IDO), red (IL-6). These color images were merged as yellow, which showed that IDO and IL-6 were co-localized in both IDO and IL-6 high expression tissues $\left(r^{2}=0.690, P<0.001\right)$.

\section{The association between IDO, IL-6 expression, plasma IL-6 level and clinicopathological features}

We analyzed the association between IDO, IL-6 expression, plasma IL-6 level and clinicopathological features of breast cancer prior neoadjuvant chemotherapy. Both higher IDO expression and plasma IL-6 level were associated with T3+T4 stage and N1-N3 stage $(P<0.05)$. Higher IL-6 expression in cancer tissues was more frequent in patients with T3+T4 stage $(P=0.016)$, shown in Table 1 . 
Then, we analyzed the association between IDO/ IL-6 co-expression and clinicopathological features prior neoadjuvant chemotherapy, which was both IDO and IL-6 high expression. The co-expression of IDO/IL-6 were correlated with advanced clinical T $(P=0.022), \mathrm{N}$ stage $(P<0.001)$, clinical stage $(P=0.002)$ and $\mathrm{ER}+(P=0.039$, shown in Table 2).

\section{The association between IDO, IL-6 expression, plasma IL-6 level and response to neoadjuvant chemotherapy}

In Table 3 and Figure 2, univariate analysis showed that IDO $(P=0.017$, Figure 2A), IL-6 expression $(P=0.031$, Figure 2B), clinical $\mathrm{T}$ stage $(P=0.031)$, ER-status $(P=0.014)$ and Luminal type $(P=0.046)$ prior neoadjuvant chemotherapy and postoperative pathological $\mathrm{T}$ stage $(P=0.042)$ were correlated with poor clinical response to neoadjuvant chemotherapy $(P<0.05)$. In this study, $P<0.05$ was considered to be statistically significant; however, the statistical significance of IL-6 $(P=0.031)$, clinical $\mathrm{T}$ stage $(P=0.031)$, pathological $\mathrm{T}$ stage $(P=0.042)$, luminal type $(P=0.046)$ were borderline. Therefore, we enrolled IDO and ER status in the multivariate analysis. Multivariate logistic regression showed that IDO $[O R=4.254(1.042 \sim 17.362), P=0.034]$ were correlated with clinical response to neoadjuvant chemotherapy.

Concentrated on the 9 patients who achieved pCR after neoadjuvant chemotherapy, only the higher IL-6 $(P=0.028$, Figure 2D) and postoperative pathological $\mathrm{T}$ stage (pT3+T4) associated with no-pCR $(P=0.012)$. So, both of them were enrolled in the multivariate analysis. The multivariate analysis logistic regression showed that only pathological $\mathrm{T}$ stage correlated with no-
pCR $[O R=7.255(1.063-49.521), P=0.041$, Table 4 and Figure 2].

\section{Prognostic analysis}

In the survival analysis, only clinical $\mathrm{T}$ stage was significant correlated with overall survival time (OS, $P=0.003$ ). Concentrating on IDO and IL-6, the patients with high IDO or IL-6 expression had poorer prognosis in comparing with low IDO $(P=0.447$ for OS and $P=0.488$ for PFS) and IL-6 expression $(P=0.506$ for OS and $P=0.378$ for PFS), patients with co-expressions of IDO/ IL-6 had shortest survival time when compared with low expression of IDO, IL-6 alone or both $(P=0.382$ for OS and $P=0.182$ for PFS). And, patients who obtained pCR had better survival than no-pCR patients $(P=0.184$ for OS and $P=0.158$ for PFS). However, all these survival differences were not statistically significant, shown in Figure 3.

\section{DISCUSSION}

Constitutive IDO activity in tumors is a core mechanism regulating immune toleration and thus deemed as an attractive therapeutic target to recover immunity against cancer. In this study, the IDO expression was correlated with advanced clinical $\mathrm{T}$ and $\mathrm{N}$ stage prior neoadjuvant chemotherapy, which was consistent with previous studies [27]. In Soliman et al's study, IDO expression was higher in ER+ tumors compared to ERtumors [22].

Okamoto et al reported that greater expression of IDO was demonstrated both in chemoresistant ovarian cancer patients and chemoresistant ovarian cancer cell lines,

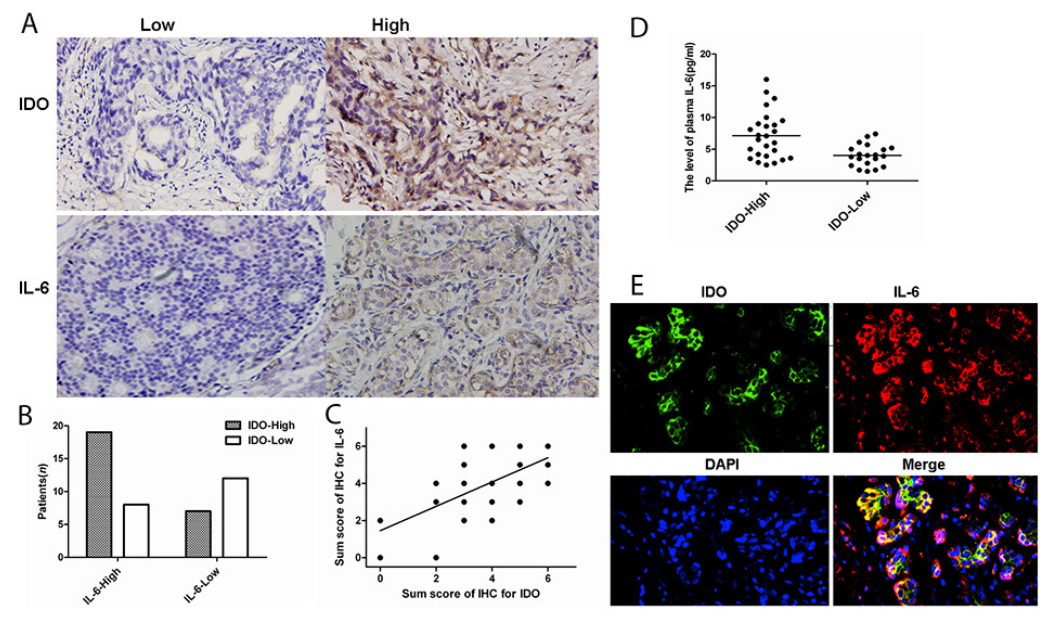

Figure 1: The association between IDO, IL-6 expression and plasma IL-6 level. (A) The expression of IDO and IL-6 in tumor tissues. (B) Patients with high IDO expression more frequently had higher IL-6 high expression. (C) By Spearman's rank correlation test, it was found that the sum score of IDO correlated with the sum score of IL-6 $\left(r^{2}=0.665, P<0.001\right)$. (D) showed that the level of plasma IL-6 in patients with high IDO expression $(7.183 \pm 3.678 \mathrm{pg} / \mathrm{mL}$, Range: $2.510 \sim 16.021 \mathrm{pg} / \mathrm{mL})$ was higher than patients with low IDO expression $(4.030 \pm 1.713 \mathrm{pg} / \mathrm{mL}$, Range: $1.495 \sim 7.487 \mathrm{pg} / \mathrm{mL}, t=3.487, P=0.001)$. (E) immunofluorescence double staining for co-localization of IDO and IL-6 in tumor tissues. 
Table 1: The association between IDO, IL-6 expression, plasma IL-6 level and clinicopathological features prior neoadjuvant chemotherapy

\begin{tabular}{|c|c|c|c|c|c|c|c|c|c|c|c|c|}
\hline \multirow{2}{*}{\multicolumn{2}{|c|}{$\begin{array}{l}\text { Clinicopathological } \\
\text { features }\end{array}$}} & \multicolumn{2}{|c|}{ IDO } & \multirow[t]{2}{*}{$x^{2}$} & \multirow[t]{2}{*}{$P$} & \multicolumn{2}{|c|}{ IL-6 } & \multirow[t]{2}{*}{$x^{2}$} & \multirow[t]{2}{*}{$P$} & \multirow{2}{*}{$\begin{array}{c}\text { Plasma IL-6 } \\
\text { Mean } \pm \mathrm{SD}\end{array}$} & \multirow[t]{2}{*}{$t$} & \multirow[t]{2}{*}{$P$} \\
\hline & & Low & High & & & Low & High & & & & & \\
\hline Age & & $45.931 \pm 12.70$ & $150.211 \pm 7.812$ & 1.429 & 0.106 & $48.000 \pm 10.951$ & $48.520 \pm 9.702$ & 0.169 & 0.866 & $7.113 \pm 4.668$ & 0.213 & 0.186 \\
\hline \multirow{2}{*}{$\begin{array}{l}\text { Menopausal } \\
\text { status }\end{array}$} & Pre- & 9 & 13 & 0.113 & 0.774 & 9 & 13 & 0.003 & 1.000 & $7.592 \pm 3.927$ & 0.852 & 0.398 \\
\hline & Post- & 11 & 13 & & & 10 & 14 & & & $6.550 \pm 4.333$ & & \\
\hline \multirow{2}{*}{$\begin{array}{l}\text { History of } \\
\text { gravidity }\end{array}$} & No & 4 & 2 & 1.510 & 0.219 & 2 & 4 & 1.181 & 1.000 & $7.627 \pm 3.827$ & 0.212 & 0.832 \\
\hline & Yes & 16 & 24 & & & 17 & 23 & & & $7.195 \pm 4.733$ & & \\
\hline \multirow{2}{*}{$\begin{array}{l}\text { Family history } \\
\text { of maligant }\end{array}$} & No & 14 & 19 & 0.053 & 1.000 & 13 & 10 & 0.176 & 0.746 & $7.752 \pm 3.771$ & 0.849 & 0.400 \\
\hline & Yes & 6 & 7 & & & 6 & 7 & & & $7.634 \pm 4.612$ & & \\
\hline \multirow[t]{2}{*}{$\begin{array}{l}\text { Clinical T } \\
\text { stage }\end{array}$} & $\mathrm{T} 1, \mathrm{~T} 2$ & 12 & 7 & 5.101 & 0.036 & 12 & 7 & 6.377 & 0.016 & $7.922 \pm 4.075$ & 2.212 & 0.032 \\
\hline & $\mathrm{T} 3, \mathrm{~T} 4$ & 8 & 19 & & & 7 & 20 & & & $5.004 \pm 4.842$ & & \\
\hline \multirow[t]{2}{*}{$\begin{array}{l}\text { Clinical N } \\
\text { stage }\end{array}$} & No & 8 & 3 & 5.033 & 0.038 & 6 & 5 & 1.046 & 0.484 & $4.804 \pm 4.765$ & 2.102 & 0.042 \\
\hline & N1-N3 & 12 & 23 & & & 13 & 22 & & & $7.809 \pm 3.877$ & & \\
\hline \multirow{2}{*}{ Clinical stage } & I, II & 7 & 4 & 2.361 & 0.309 & 5 & 6 & 0.103 & 0.749 & $7.2927 \pm 4.271$ & 0.362 & 0.718 \\
\hline & III, IV & 13 & 22 & & & 14 & 21 & & & $6.775 \pm 4.0738$ & & \\
\hline \multirow{2}{*}{$\begin{array}{l}\text { Histological } \\
\text { type }\end{array}$} & IDBC & 17 & 21 & 0.141 & 1.000 & 16 & 22 & 0.058 & 1.000 & $7.112 \pm 4.018$ & 0.150 & 0.881 \\
\hline & Other & 3 & 5 & & & 3 & 5 & & & $6.875 \pm 4.2738$ & & \\
\hline \multirow[t]{2}{*}{ ER-status } & - & 11 & 7 & 3.741 & 0.073 & 6 & 12 & 0.775 & 0.541 & $7.414 \pm 3.980$ & 0.511 & 0.611 \\
\hline & + & 9 & 19 & & & 13 & 15 & & & $6.9784 \pm .1738$ & & \\
\hline \multirow[t]{2}{*}{ PR } & - & 9 & 13 & 0.113 & 0.774 & 11 & 13 & 0.425 & 0.562 & $7.525 \pm 4.98$ & 0.931 & 0.356 \\
\hline & + & 11 & 13 & & & 8 & 14 & & & $6.1878 \pm 4.738$ & & \\
\hline \multirow[t]{2}{*}{ Her-2 } & - & 15 & 14 & 2.171 & 0.219 & 14 & 15 & 1.573 & 0.235 & $6.025 \pm 4.980$ & 1.174 & 0.247 \\
\hline & + & 5 & 12 & & & 5 & 12 & & & $7.781 \pm 4.738$ & & \\
\hline \multirow[t]{2}{*}{ Ki67 } & - & 9 & 9 & 0.512 & 0.550 & 9 & 9 & 0.992 & 0.373 & $5.871 \pm 3.738$ & 1.460 & 0.150 \\
\hline & + & 11 & 17 & & & 10 & 18 & & & $7.761 \pm 5.028$ & & \\
\hline \multirow[t]{2}{*}{ P53 protein } & - & 9 & 12 & 0.006 & 1.000 & 9 & 12 & 0.038 & 1.000 & $5.973 \pm 4.527$ & 1.600 & 0.246 \\
\hline & + & 11 & 14 & & & 10 & 15 & & & $7.775 \pm 3.074$ & & \\
\hline \multirow[t]{3}{*}{ Luminal type } & Luminal & 13 & 17 & 0.425 & 0.809 & 13 & 17 & 1.865 & 0.394 & $4.530 \pm 4.172$ & 0.745 & 0.482 \\
\hline & Her-2 & 5 & 5 & & & 5 & 5 & & & $7.351 \pm 4.411$ & & \\
\hline & $\begin{array}{l}\text { Basal- } \\
\text { like }\end{array}$ & 1 & 3 & & & 1 & 5 & & & $8.331 \pm 6.823$ & & \\
\hline
\end{tabular}

IDBC: Invasive ductal breast cancer. For categorical variables, the $x^{2}$ value and $P$ value were calculated by Chi-square tests. For continuous variables, values are given as mean \pm standard deviation and compared with independent $t$-test.

suggesting that IDO may participate in chemosensitivity via intracellular pathways [17]. IDO expression was downregulated by nitric oxide, which is known to mediate chemosensitivity in tumor cells by salvaging product of mass cytosolic superoxide anions [23]. Therefore, Okamoto et al. suggested that the expression of IDO may be an accompanied phenomenon to other promoting mechanisms of chemoresistance, for example nitric oxide production, but not induce chemoresistance directly [17]. Muller et al. reported that IDO inhibitor combined with different chemotherapeutic drugs can induce regression of recurrent breast cancers more effectively [16]. In addition, Inaba et al confirmed that treatment with 1-MT, the inhibitor of IDO1, combined with paclitaxel congenially prolonged 
Table 2: The association between IDO/IL-6 co-expression and clinicopathological features prior neoadjuvant chemotherapy

\begin{tabular}{|c|c|c|c|c|c|c|c|c|}
\hline Clinicopathological features & & $n$ & IDO-/IL-6- & IDO+/IL-6- & IDO-/IL-6+ & IDO+/IL-6+ & $x^{2}$ & $P$ \\
\hline Total $(n)$ & & 46 & 13 & 6 & 7 & 20 & & \\
\hline Age & & 46 & $48.38 \pm 12.21$ & $47.17 \pm 8.542$ & $41.29 \pm 11.91$ & $51.05 \pm 7.619$ & 1.716 & 0.178 \\
\hline \multirow[t]{2}{*}{ Menopausal status } & Pre- & 22 & 7 & 2 & 2 & 11 & 2.146 & 0.543 \\
\hline & Post- & 24 & 6 & 4 & 5 & 9 & & \\
\hline \multirow[t]{2}{*}{ History of gravidity } & No & 6 & 1 & 1 & 3 & 1 & 7.024 & 0.071 \\
\hline & Yes & 40 & 12 & 5 & 4 & 19 & & \\
\hline \multirow[t]{2}{*}{ Family history of maligant } & No & 33 & 9 & 4 & 5 & 15 & 0.222 & 0.974 \\
\hline & Yes & 13 & 4 & 2 & 2 & 5 & & \\
\hline \multirow[t]{2}{*}{ Clinical T stage } & $\mathrm{T} 1, \mathrm{~T} 2$ & 19 & 10 & 2 & 2 & 5 & 9.621 & 0.022 \\
\hline & $\mathrm{T} 3, \mathrm{~T} 4$ & 27 & 3 & 4 & 5 & 15 & & \\
\hline \multirow[t]{2}{*}{ Clinical N stage } & N0 & 11 & 2 & 4 & 5 & 0 & 21.519 & $<0.001$ \\
\hline & N1-N3 & 35 & 11 & 2 & 2 & 20 & & \\
\hline \multirow[t]{2}{*}{ Clinical stage } & I, II & 11 & 2 & 3 & 5 & 1 & 15.382 & 0.002 \\
\hline & III, IV & 35 & 11 & 3 & 2 & 19 & & \\
\hline \multirow[t]{2}{*}{ Histological type } & IDBC & 38 & 12 & 4 & 5 & 17 & 2.601 & 0.457 \\
\hline & Other & 8 & 1 & 2 & 2 & 3 & & \\
\hline \multirow[t]{2}{*}{ ER } & - & 18 & 5 & 1 & 6 & 6 & 8.351 & 0.039 \\
\hline & + & 28 & 8 & 5 & 1 & 14 & & \\
\hline \multirow[t]{2}{*}{ PR } & - & 22 & 8 & 3 & 3 & 8 & 1.551 & 0.671 \\
\hline & + & 24 & 5 & 3 & 4 & 12 & & \\
\hline \multirow[t]{2}{*}{ Her-2 } & - & 29 & 9 & 5 & 6 & 9 & 5.613 & 0.132 \\
\hline & + & 17 & 4 & 1 & 1 & 11 & & \\
\hline \multirow[t]{2}{*}{ Ki67 } & - & 18 & 6 & 3 & 3 & 6 & 1.308 & 0.727 \\
\hline & + & 28 & 7 & 3 & 4 & 14 & & \\
\hline \multirow[t]{2}{*}{ P53 } & - & 21 & 5 & 4 & 4 & 8 & 1.969 & 0.579 \\
\hline & + & 25 & 8 & 2 & 3 & 12 & & \\
\hline \multirow[t]{3}{*}{ Luminal type } & Luminal & 30 & 8 & 5 & 4 & 13 & 3.585 & 0.733 \\
\hline & Her-2 & 10 & 4 & 1 & 1 & 4 & & \\
\hline & $\begin{array}{c}\text { Basal- } \\
\text { like }\end{array}$ & 6 & 1 & 0 & 2 & 3 & & \\
\hline
\end{tabular}

IDBC: Invasive ductal breast cancer. For categorical variables, the $x^{2}$ value and $P$ value were calculated by Chi-square tests. For continuous variables, values are given as mean \pm standard deviation and compared with independent $t$-test.

mouse survival compared to treatment with paclitaxel alone in an IDO1 high expressing ovarian cancer peritoneal carcinomatosis female C57BL/6 mice [24]. Salvador et al reported that combination 1-MT with paclitaxel would promote remodeling of $\mathrm{T}$ lymphocyte proliferation capability and its cytotoxic response [25].
All these reports indicated that IDO is positively associated with chemotherapy resistance and impaired survival. Muller et al. indicated that Bin1 loss increased the STAT1 and NF-kB dependent IDO expression [16], while the NF-kB activation suppresses the apoptotic potential of chemotherapeutic agents [26]. In our study, 
Table 3: The association between IDO, IL-6 expression plasma IL-6 level and clinicopathological features with CR+PR

\begin{tabular}{|c|c|c|c|c|c|c|c|c|c|c|}
\hline \multicolumn{2}{|c|}{ Clinicopathological features } & \multirow[t]{2}{*}{$n$} & \multirow{2}{*}{$\frac{\mathbf{C R}+\mathbf{P R} \text { (n) }}{48.52 \pm 11.27}$} & \multirow{2}{*}{$\frac{\text { PD+SD (n) }}{48.05 \pm 10.26}$} & \multirow{2}{*}{$\frac{x^{2}}{0.877}$} & \multirow{2}{*}{$\frac{P}{0.472}$} & \multirow{2}{*}{$\frac{\mathrm{OR}(\mathbf{9 5 \%} \boldsymbol{C I})}{0.995(0.939-1.005)}$} & \multirow{2}{*}{$\frac{P}{0.873}$} & \multirow[t]{2}{*}{ OR $(95 \% C I)$} & \multirow[t]{2}{*}{$P$} \\
\hline Age & & & & & & & & & & \\
\hline \multirow[t]{2}{*}{$\begin{array}{l}\text { Menopausal } \\
\text { status }\end{array}$} & Pre- & 22 & 14 & 8 & 1.446 & 0.253 & $0.484(0.148-1.578)$ & 0.229 & & \\
\hline & Post- & 24 & 11 & 13 & & & 1 & & & \\
\hline \multirow[t]{2}{*}{$\begin{array}{l}\text { History of } \\
\text { gravidity }\end{array}$} & No & 6 & 4 & 2 & 0.422 & 0.673 & $0.553(0.091-3.368)$ & 0.520 & & \\
\hline & Yes & 40 & 21 & 19 & & & 1 & & & \\
\hline \multirow{2}{*}{$\begin{array}{l}\text { Family history } \\
\text { of maligant }\end{array}$} & No & 33 & 17 & 16 & 0.378 & 0.539 & $1.506(0.407-5.578)$ & 0.540 & & \\
\hline & Yes & 13 & 8 & 5 & & & 1 & & & \\
\hline \multirow[t]{2}{*}{ IDO } & Low & 20 & 15 & 5 & 6.083 & 0.019 & $0.208(0.028-0.752)$ & 0.017 & $\begin{array}{c}4.254 \\
(1.042 \sim 17.362)\end{array}$ & 0.034 \\
\hline & High & 26 & 10 & 16 & & & 1 & & 1 & \\
\hline \multirow[t]{2}{*}{ IL-6 } & Low & 19 & 14 & 5 & 4.878 & 0.038 & $0.246(0.068-0.881)$ & 0.031 & & \\
\hline & High & 27 & 11 & 16 & & & 1 & & & \\
\hline $\begin{array}{l}\text { Plasma IL-6 } \\
\text { level }\end{array}$ & & 46 & $6.681 \pm 4.033$ & $8.891 \pm 3.879$ & 1.904 & 0.063 & $0.980(0.957-1.003)$ & 0.093 & & \\
\hline \multirow[t]{4}{*}{ IDO/IL-6 } & IDO-low/IL-6-low & 13 & 12 & 1 & 10.650 & 0.014 & $0.056(0.006-0.515)$ & 0.068 & & \\
\hline & IDO-highIL-6-low & 6 & 2 & 4 & & & $1.333(0.196-9.083)$ & 0.011 & & \\
\hline & IDO-low/IL-6-high & 7 & 3 & 4 & & & $0.889(0.155-5.084)$ & 0.769 & & \\
\hline & IDO-high/IL-6-high & 20 & 8 & 12 & & & 1 & 0.895 & & \\
\hline \multirow[t]{2}{*}{$\begin{array}{l}\text { Clinical T } \\
\text { stage }\end{array}$} & $\mathrm{T} 1, \mathrm{~T} 2$ & 19 & 14 & 5 & 4.878 & 0.038 & $4.073(1.635-14.632)$ & 0.031 & & \\
\hline & $\mathrm{T} 3, \mathrm{~T} 4$ & 27 & 11 & 16 & & & 1 & & & \\
\hline \multirow[t]{2}{*}{$\begin{array}{l}\text { Clinical N } \\
\text { stage }\end{array}$} & No & 11 & 4 & 7 & 1.885 & 0.298 & $0.381(0.094-1.548)$ & 0.177 & & \\
\hline & N1-N3 & 35 & 21 & 14 & & & 1 & & & \\
\hline \multirow[t]{2}{*}{ Clinical stage } & $\mathrm{I}+\mathrm{II}$ & 11 & 5 & 6 & 0.461 & 0.730 & $0.625(0.160-2.441)$ & 0.499 & & \\
\hline & $\mathrm{III}+\mathrm{IV}$ & 35 & 20 & 15 & & & 1 & & & \\
\hline \multirow[t]{2}{*}{$\begin{array}{l}\text { Pathological T } \\
\text { stage }\end{array}$} & $\mathrm{pT} 1, \mathrm{~T} 2$ & 36 & 23 & 13 & 4.076 & 0.043 & $0.141(0.026-0.717)$ & 0.042 & & \\
\hline & pT3, T4 & 10 & 2 & 8 & & & 1 & & & \\
\hline \multirow[t]{2}{*}{$\begin{array}{l}\text { Pathological N } \\
\text { stage }\end{array}$} & $\mathrm{pN} 0$ & 8 & 4 & 4 & 0.074 & 1.000 & $0.810(0.176-3.125)$ & 0.786 & & \\
\hline & $\mathrm{pN} 1-\mathrm{N} 3$ & 38 & 21 & 17 & & & 1 & & & \\
\hline \multirow[t]{2}{*}{$\begin{array}{l}\text { Pathological } \\
\text { stage }\end{array}$} & $\mathrm{I}+\mathrm{II}$ & 16 & 8 & 8 & 0.187 & 0.760 & $0.765(0.226-2.583)$ & 0.666 & & \\
\hline & $\mathrm{III}+\mathrm{IV}$ & 30 & 17 & 13 & & & 1 & & & \\
\hline \multirow[t]{2}{*}{$\begin{array}{l}\text { Histological } \\
\text { type }\end{array}$} & IDBC & 38 & 21 & 17 & 0.074 & 1.000 & $1.253(0.268-5.648)$ & 0.786 & & \\
\hline & Other & 8 & 4 & 4 & & & 1 & & & \\
\hline ER & - & 18 & 14 & 4 & 6.543 & 0.016 & $5.409(1.409-20.768)$ & 0.014 & $\begin{array}{c}3.739 \\
(0.966 \sim 14.465)\end{array}$ & 0.056 \\
\hline
\end{tabular}

(Continued) 


\begin{tabular}{|c|c|c|c|c|c|c|c|c|c|c|}
\hline \multicolumn{2}{|c|}{ Clinicopathological features } & \multirow{2}{*}{$\frac{n}{28}$} & \multirow{2}{*}{$\frac{\mathbf{C R}+\mathbf{P R} \text { (n) }}{11}$} & \multirow{2}{*}{$\frac{\mathbf{P D}+\mathbf{S D}(\mathbf{n})}{17}$} & \multirow[t]{2}{*}{$x^{2}$} & \multirow[t]{2}{*}{$P$} & \multirow{2}{*}{$\frac{\text { OR }(95 \% C I)}{1}$} & \multirow[t]{2}{*}{$P$} & \multirow[t]{2}{*}{ OR $(95 \% C I)$} & \multirow[t]{2}{*}{$\boldsymbol{P}$} \\
\hline & + & & & & & & & & & \\
\hline \multirow[t]{2}{*}{ PR } & - & 22 & 15 & 7 & 3.253 & 0.085 & $3.000(0.895-10.085)$ & 0.075 & & \\
\hline & + & 24 & 10 & 14 & & & 1 & & & \\
\hline \multirow[t]{2}{*}{ Her-2 } & - & 29 & 14 & 15 & 1.166 & 0.363 & $0.509(0.148-1.747)$ & 0.283 & & \\
\hline & + & 17 & 11 & 6 & & & 1 & & & \\
\hline \multirow[t]{2}{*}{ Ki67 } & - & 18 & 11 & 7 & 0.545 & 0.551 & $1.571(0.472-5.232)$ & 0.461 & & \\
\hline & + & 28 & 14 & 14 & & & 1 & & & \\
\hline \multirow[t]{2}{*}{ P53 } & - & 21 & 11 & 10 & 0.060 & 1.000 & $0.846(0.270-2.771)$ & 0.806 & & \\
\hline & + & 25 & 14 & 11 & & & 1 & & & \\
\hline \multirow[t]{4}{*}{ Luminal type } & Luminal & 30 & 12 & 18 & 7.979 & 0.019 & $3.000(0.473-19.039)$ & 0.046 & & \\
\hline & Her-2 & 10 & 9 & 1 & & & $0.222(0.015-3.221)$ & 0.244 & & \\
\hline & Basal-like & 6 & 4 & 2 & & & 1 & 0.270 & & \\
\hline & TAC/TEC & 33 & 20 & 13 & 1.970 & 0.373 & $0.650(0.037-11.332)$ & 0.386 & & \\
\hline \multirow[t]{2}{*}{$\begin{array}{l}\text { Chemotherapy } \\
\text { regime }\end{array}$} & $\mathrm{TA} / \mathrm{TE}$ & 11 & 4 & 7 & & & $1.750(0.084-36.287)$ & 0.768 & & \\
\hline & Other & 2 & 1 & 1 & & & 1 & 0.718 & & \\
\hline \multirow[t]{2}{*}{$\begin{array}{l}\text { Chemotherapy } \\
\text { cycles }\end{array}$} & 2 cycles & 33 & 21 & 12 & 4.060 & 0.056 & $0.254(0.164-1.004)$ & 0.052 & & \\
\hline & $\geq 3$ cycles & 13 & 4 & 9 & & & 1 & & & \\
\hline
\end{tabular}

IDBC: Invasive ductal breast cancer. For categorical variables, the $x^{2}$ value and $P$ value were calculated by Chi-square tests. For continuous variables, values are given as mean \pm standard deviation and compared with independent $t$-test.

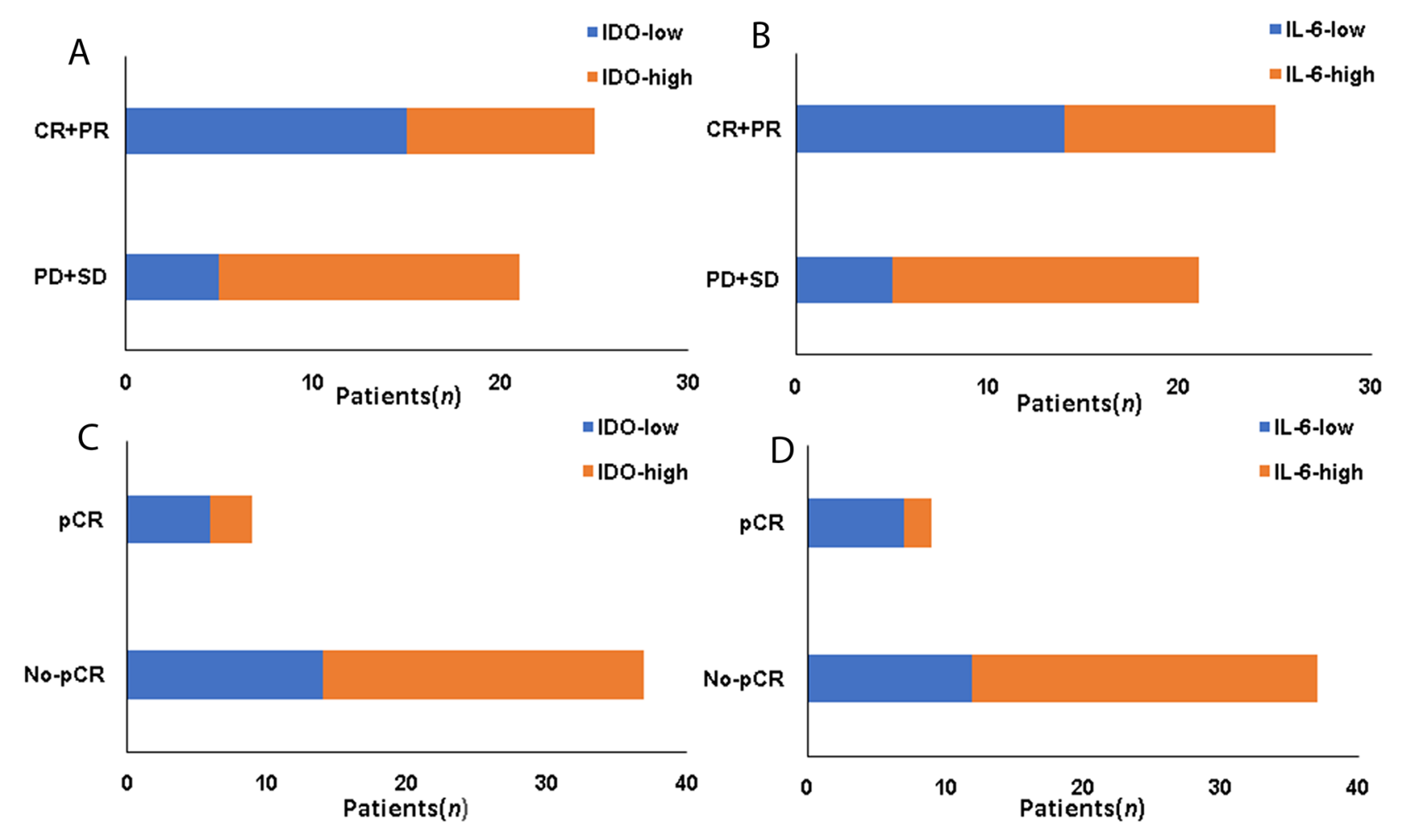

Figure 2: The association between IDO, IL-6 expression and response to neoadjuvant chemotherapy. (A) The association between IDO and CR+PR. (B) The association between IL-6 and CR+PR. (C) The association between IDO and pCR. (D) The association between IL-6 and pCR. 
Table 4: The association between IDO, IL-6 expression plasma IL-6 level and clinicopathological features with pCR

\begin{tabular}{|c|c|c|c|c|c|c|c|c|c|c|}
\hline \multicolumn{2}{|c|}{ Clinicopathological features } & \multirow{2}{*}{$\frac{n}{46}$} & \multirow{2}{*}{$\frac{\text { pCR (n) }}{48.52 \pm 11.27}$} & \multirow{2}{*}{$\frac{\text { No-pCR (n) }}{48.05 \pm 10.26}$} & \multirow{2}{*}{$\frac{x^{2}}{0.877}$} & \multirow{2}{*}{$\frac{P}{0.472}$} & \multirow{2}{*}{$\begin{array}{c}\text { OR }(95 \% C I) \\
1.031(1.955-1.114)\end{array}$} & \multirow{2}{*}{$\frac{P}{0.433}$} & \multirow[t]{2}{*}{ OR $(95 \% C I)$} & \multirow[t]{2}{*}{$P$} \\
\hline Age & & & & & & & & & & \\
\hline \multirow[t]{2}{*}{ Menopausal status } & Pre- & 22 & 4 & 18 & 0.051 & 0.821 & $1.184(0.274-5.121)$ & 0.821 & & \\
\hline & Post- & 24 & 5 & 19 & & & 1 & & & \\
\hline \multirow[t]{2}{*}{$\begin{array}{l}\text { History of } \\
\text { gravidity }\end{array}$} & No & 6 & 8 & 32 & 0.037 & 0.848 & $0.800(0.082-7.841)$ & 0.848 & & \\
\hline & Yes & 40 & 1 & 5 & & & 1 & & & \\
\hline \multirow{2}{*}{$\begin{array}{l}\text { Family history of } \\
\text { maligant }\end{array}$} & No & 33 & 1 & 12 & 1.623 & 0.203 & $3.840(0.340-34.306)$ & 0.229 & & \\
\hline & Yes & 13 & 8 & 25 & & & 1 & & & \\
\hline \multirow[t]{2}{*}{ IDO } & Low & 20 & 6 & 14 & 2.448 & 0.149 & $3.316(0.607-18.124)$ & 0.167 & & \\
\hline & High & 26 & 3 & 23 & & & 1 & & & \\
\hline \multirow[t]{2}{*}{ IL-6 } & Low & 19 & 7 & 12 & 6.140 & 0.022 & $7.579(1.060-66.813)$ & 0.028 & $\begin{array}{c}1.754(0.285- \\
10.801)\end{array}$ & 0.545 \\
\hline & High & 27 & 2 & 25 & & & 1 & & 1 & \\
\hline Plasma IL-6 level & & 46 & $5.775 \pm 2.0738$ & $7.2927 \pm 3.527$ & 1.232 & 0.224 & $1.006(0.982-1.031)$ & 0.616 & & \\
\hline \multirow[t]{4}{*}{ IDO/IL-6 } & IDO-low/IL-6-low & 13 & 12 & 1 & 10.650 & 0.014 & $0.155(0.017-1.450)$ & 0.359 & & \\
\hline & IDO-highIL-6-low & 6 & 2 & 4 & & & 0.000 & 0.102 & & \\
\hline & IDO-low/IL-6-high & 7 & 3 & 4 & & & $0.310(0.031-3.111)$ & 0.999 & & \\
\hline & IDO-high/IL-6-high & 20 & 8 & 12 & & & 1 & 0.319 & & \\
\hline \multirow[t]{2}{*}{ Clinical T stage } & $\mathrm{T} 1, \mathrm{~T} 2$ & 19 & 4 & 15 & 0.461 & 0.831 & $0.852(0.196-3.705)$ & 0.831 & & \\
\hline & $\mathrm{T} 3, \mathrm{~T} 4$ & 27 & 5 & 22 & & & 1 & & & \\
\hline \multirow[t]{2}{*}{ Clinical N stage } & No & 11 & 1 & 10 & 1.008 & 0.421 & $2.963(0.328-26.790)$ & 0.334 & & \\
\hline & N1-N3 & 35 & 8 & 27 & & & 1 & & & \\
\hline \multirow[t]{2}{*}{ Clinical stage } & $\mathrm{I}+\mathrm{II}$ & 11 & 1 & 10 & 1.008 & 0.235 & $2.963(0.328-26.790)$ & 0.334 & & \\
\hline & $\mathrm{III}+\mathrm{IV}$ & 35 & 8 & 27 & & & 1 & & & \\
\hline \multirow[t]{2}{*}{$\begin{array}{l}\text { Pathological T } \\
\text { stage }\end{array}$} & $\mathrm{pT} 0, \mathrm{~T} 1, \mathrm{~T} 2$ & 36 & 4 & 32 & 7.521 & 0.006 & $8.000(1.587-40.332)$ & 0.012 & $\begin{array}{c}7.255(1.063- \\
49.521)\end{array}$ & 0.041 \\
\hline & pT3, T4 & 10 & 5 & 5 & & & 1 & & 1 & \\
\hline \multirow[t]{2}{*}{$\begin{array}{l}\text { Pathological N } \\
\text { stage }\end{array}$} & $\mathrm{pN} 0$ & 8 & 2 & 6 & 0.182 & 0.670 & $0.677(0.112-4.091)$ & 0.671 & & \\
\hline & $\mathrm{pN} 1-\mathrm{N} 3$ & 38 & 7 & 31 & & & & & & \\
\hline \multirow[t]{2}{*}{ Pathological stage } & $\mathrm{I}+\mathrm{II}$ & 16 & 8 & 8 & 0.187 & 0.760 & $0.338(0.076-1.505)$ & 0.155 & & \\
\hline & $\mathrm{III}+\mathrm{IV}$ & 30 & 17 & 13 & & & 1 & & & \\
\hline \multirow[t]{2}{*}{ Histological type } & IDBC & 38 & 5 & 11 & 2.128 & 0.124 & 0.000 & 0.999 & & \\
\hline & Other & 8 & 4 & 24 & & & 1 & & & \\
\hline \multirow[t]{2}{*}{ ER } & - & 18 & 2 & 16 & 3.883 & 0.055 & $6.880(0.771-59.980)$ & 0.074 & & \\
\hline & + & 28 & 7 & 21 & & & 1 & & & \\
\hline \multirow[t]{2}{*}{ PR } & - & 22 & 4 & 18 & 0.051 & 0.821 & $1.184(0.274-5.121)$ & 0.821 & & \\
\hline & + & 24 & 5 & 19 & & & 1 & & & \\
\hline Her-2 & - & 29 & 5 & 24 & 0.269 & 0.604 & $1.477(0.337-6.474)$ & 0.605 & & \\
\hline & + & 17 & 4 & 13 & & & 1 & & & \\
\hline
\end{tabular}

(Continued) 


\begin{tabular}{|c|c|c|c|c|c|c|c|c|c|c|}
\hline \multicolumn{2}{|c|}{ Clinicopathological features } & \multirow{2}{*}{$\frac{n}{18}$} & \multirow{2}{*}{$\frac{\text { pCR (n) }}{4}$} & \multirow{2}{*}{$\frac{\text { No-pCR (n) }}{14}$} & \multirow{2}{*}{$\frac{x^{2}}{0.133}$} & \multirow{2}{*}{$\frac{P}{0.716}$} & \multirow{2}{*}{$\begin{array}{c}\text { OR }(95 \% C I) \\
0.761(0.174-3.310)\end{array}$} & \multirow{2}{*}{$\frac{P}{0.716}$} & \multirow[t]{2}{*}{ OR $(95 \% C I)$} & \multirow[t]{2}{*}{$P$} \\
\hline Ki67 & - & & & & & & & & & \\
\hline & + & 28 & 5 & 23 & & & 1 & & & \\
\hline \multirow[t]{2}{*}{ P53 } & - & 21 & 2 & 19 & 2.476 & 0.116 & $3.694(0.676-20.694)$ & 0.132 & & \\
\hline & + & 25 & 7 & 18 & & & 1 & & & \\
\hline \multirow[t]{3}{*}{ Luminal type } & Luminal & 30 & 6 & 24 & 1.308 & 0.520 & $0.500(0.073-3.406)$ & 0.541 & & \\
\hline & Her-2 & 10 & 1 & 9 & & & $0.222(0.015-3.221)$ & 0.479 & & \\
\hline & Basal-like & 6 & 2 & 4 & & & 1 & 0.270 & & \\
\hline \multirow[t]{3}{*}{$\begin{array}{l}\text { Chemotherapy } \\
\text { regime }\end{array}$} & TAC/TEC & 33 & 8 & 25 & 1.712 & 0.425 & $5.169 \times 10^{9}$ & 0.586 & & \\
\hline & $\mathrm{TA} / \mathrm{TE}$ & 11 & 1 & 10 & & & $1.615 \times 10^{9}$ & 0.999 & & \\
\hline & Other & 2 & 0 & 2 & & & 1 & 0.999 & & \\
\hline \multirow[t]{2}{*}{$\begin{array}{l}\text { Chemotherapy } \\
\text { cycles }\end{array}$} & 2 cycles & 33 & 8 & 25 & 1.623 & 0.410 & $0.260(0.029-2.327)$ & 0.229 & & \\
\hline & $\geq 3$ cycles & 13 & 1 & 2 & & & 1 & & & \\
\hline
\end{tabular}

IDBC: Invasive ductal breast cancer. For categorical variables, the $x^{2}$ value and $P$ value were calculated by Chi-square tests. For continuous variables, values are given as mean \pm standard deviation and compared with independent $t$-test.

Table 5: The summary of clinicopathological characteristics

\begin{tabular}{|c|c|c|}
\hline Clinicopathological characteristics & & $n$ \\
\hline Age $(n$, Mean \pm SD year $)$ & & $46(48.33 \pm 13.16)$ \\
\hline Menopausal status & Pre-/post & $22 / 24$ \\
\hline History of gravidity & $\mathrm{No} / \mathrm{Yes}$ & $6 / 40$ \\
\hline Family history of maligant & $\mathrm{No} / \mathrm{Yes}$ & $33 / 13$ \\
\hline Clinical T stage & $\mathrm{T} 1 / \mathrm{T} 2 / \mathrm{T} 3 / \mathrm{T} 4$ & $1 / 18 / 14 / 13$ \\
\hline Clinical N stage & $\mathrm{N} 0 / \mathrm{N} 1 / \mathrm{N} 2 / \mathrm{N} 3$ & $11 / 10 / 12 / 13$ \\
\hline Clinical stage & I/II/ III/IV & $1 / 10 / 35 / 0$ \\
\hline Pathological T stage & $\mathrm{pT} 0 / \mathrm{T} 1 / \mathrm{T} 2 / \mathrm{T} 3 / \mathrm{T} 4$ & $2 / 20 / 14 / 8 / 2$ \\
\hline Pathological N stage & $\mathrm{pN} 0 / \mathrm{N} 1 / \mathrm{N} 2 / \mathrm{N} 3$ & $8 / 18 / 11 / 9$ \\
\hline Pathological stage & I/II/III/IV & $5 / 22 / 19 / 0$ \\
\hline Histological type & IDBC/ ILC/ IPC/IBC & $38 / 5 / 1 / 1$ \\
\hline ER & $-/+$ & $18 / 28$ \\
\hline PR & $-/+$ & $22 / 24$ \\
\hline Her-2 & $-/+$ & $29 / 17$ \\
\hline Ki67 & $-/+$ & $18 / 28$ \\
\hline P53 & $-/+$ & $21 / 25$ \\
\hline Luminal subtypes & Luminal/Her-2/Basal-like & $30 / 10 / 6$ \\
\hline Chemotherapy regime & $\begin{array}{c}\text { TAC or TEC/ TA or TE/EC/ } \\
\text { CMF }\end{array}$ & $33 / 11 / 1 / 1$ \\
\hline Chemotherapy cycles & 2 cycles $/ \geq 3$ cycles & $33 / 13$ \\
\hline
\end{tabular}

IDBC: Invasive ductal breast cancer; ILC: Invasive lobular carcinoma; IPC: Invasive papillary carcinoma; IBC:

Inflammatory breast cancer. Luminal subtypes was by immunohistochemical method and included HER2 negative luminal type (luminal: HER2-negative and hormone receptor positive), HER2 positive type (HER2: HER2 positive irrespective of hormone receptors status), and triple negative (TN) type (Basal-like: negative for hormone receptors and HER2). 
high IDO expression correlated with poorer clinical response $(\mathrm{PD}+\mathrm{SD})$ to neoadjuvant chemotherapy.

Higher levels of serum IL-6 are associated with aggressive cancer and response to therapies in series malignant tumors. Patients with high levels of serum IL-6 are also generally associated with poor prognosis and shorter survival $[8,27,36,41]$. In this study, higher plasma IL-6 level was associated with advanced clinical T stage and $\mathrm{N}$ stage. IL-6 expression of cancer tissues was associated with advanced clinical $\mathrm{T}$ stage.

IL-6 secreted from either cancer cells or tumor microenvironment (immune cells and tumor stromal cells) not only facilitates tumor growth but also acts as a major barrier in achieving therapeutic efficacy [28]. Serum IL-6 levels have been reported to be associated with a poor prognosis and treatment failure in patient with many different carcinomas [29]. In prostate cancer, inhibition of IL-6 secretion increases the sensitivity of prostate cancer cells to anticancer drugs [30]. Previous study found that prostate cancer patients who responded to docetaxel and zolendronic acid therapy had a $35 \%$ decrease in overall serum IL-6 levels, while patients who did not respond had an increasing in serum IL-6 levels, which implied IL-6 regulate chemo-resistance in prostate cancer [8, 11]. The autocrine secretion of IL-6 by tumor cells is also confirmed to contribute to chemo-resistance; further studies demonstrated that drug sensitive tumor cells do not or low express IL-6, yet, multidrug resistant breast cancer cells secreted more IL-6 [31]. In this study, the low IL-6 expression was also associated with both clinical response and pathological response ( $\mathrm{PR}+\mathrm{CR}$ and $\mathrm{pCR}$ ).

IL-6-mediated STAT3 activation has been reported to induce chemotherapy resistance in tumors by several pathways [11, 12]. IL-6 induced drug resistance is associated with increased expression of the multidrug resistance gene, mdr1, and upregulation of $\mathrm{C} / \mathrm{EBP} \beta$ and $\mathrm{C} / \mathrm{EBP} \delta$ (CCAAT enhancer-binding protein family of transcription factors) [31]. In Patel et al. study, IL-6 secreted from stromal cells induces CYP2E1 and CYP1B1 expression through the JAK/STAT and PI3K/AKT pathways, which causes tumor occurrence and progression by chemical carcinogens [13]. IL-6 also down regulate clinical outcome by maintaining abundant therapeutic resistant cancer stem cells which is play crucial role in tumor reoccurrence and resistance [32].

IDO was demonstrated to drive IL-6 production in lung cancer and metastatic breast cancer (Lox-Stop-Lox $\mathrm{Kras}^{\mathrm{G} 12 \mathrm{D}}$ transgenic mice) [33], while IL-6 was confirmed to promote IDO expression via JAK/STAT signaling pathway [20]. In this study, high IDO expression was correlated with high IL-6 expression both in breast cancer tissues and serum. Immunofluorescence double staining
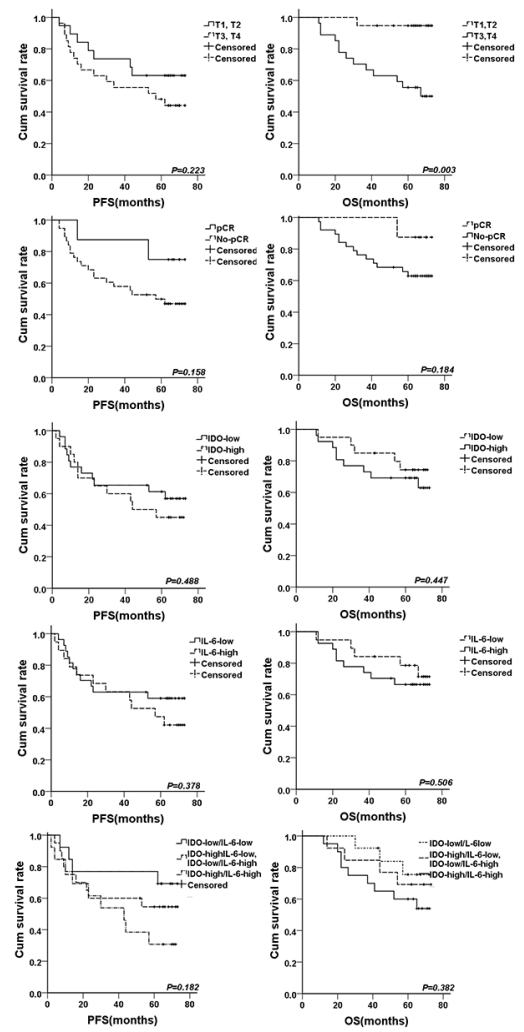

Figure 3: The survival curves for breast cancer patients treated by neoadjuvant chemotherapy. The survival curves for PFS and OS according to different clinical T stage, pCR, IDO expression, IL-6 expression, IDO/IL-6 co-expression were shown. 
showed that IDO and IL-6 can be co-localized in IDO and IL-6 high expression tissues. Litzenburger et al suggested that the IDO-AHR-IL-6-STAT3 transcriptional loop represents a complex network of positive feedback [21]. In immune research, Hofer et al found that this positive feedback loop can cooperate a bistable system [34], which can be in a steady off-state, and all composes of this loop have only basal activity under the threshold for self-amplification, or in a steady on-state, the high activity of all composes is self maintained by positive feedback and limited only by sustaining degradation and inactivation [21]. We analyzed the association between IDO/IL-6 co-expression and clinicopathological features prior neoadjuvant chemotherapy. The co-expression of IDO/IL-6 was correlated with advanced clinical T, $\mathrm{N}$ stage and $\mathrm{ER}+$.

In breast cancer tissues, IDO expression was correlated with IL-6 expression. Both of them were associated with clinicopathological features and response to chemotherapy. These findings suggested that IDO and IL-6 play important role in cancer progress and chemotherapy efficacy which maybe predictable markers for the chemotherapy response to aid clinical decisionmaking of more effective therapies for breast cancer. Additionally, immunotherapy therapies which inhibit IL-6 and IDO maybe rational agents of comprehensive treatment to improve outcome of chemotherapy. Particularly, agents targeting IDO (epacadostat, indoximod et al) as a standalone therapeutic agent often fails to prevent disease progression. However, IDO inhibitors have been evaluated for their ability to improve the efficacy of multiple chemotherapeutics, and some combinatorial regimens had promising results in preclinical studies [35].

But this study had many limitations. Firstly, this was a retrospective study, which can't randomly select patients and set control groups. What's more, research sample is relatively less, especially, only 9 patients achieved $\mathrm{pCR}$, and all participants were from our center, which contributed to few significant difference of $\mathrm{pCR}$ analysis and prognostic analysis. In order to a more practical result, further clinical researches with larger sample and from multi-center are required. In addition, these data are only correlative analysis and further experimental study of molecular biology is required to reveal the interaction mechanisms of IDO and IL-6.

\section{MATERIALS AND METHODS}

\section{Patients}

This study was a retrospective study followed the REMARK criteria for biomarkers [35]. Inclusive criteria of patients included: (1) Patients with breast cancer registered in the Department of Breast Oncology of Tianjin Medical University Cancer Institute and Hospital between $1^{\text {st }}$, January, 2011-31 $1^{\text {st }}$, August, 2011, and completed at least 5 years following-up; (2) Patients underwent coarse needle biopsies prior neoadjuvant chemotherapy and obtained at least three tissue cylinders for repeating at least triple $\mathrm{H} \& \mathrm{E}$ staining in pathological examination and immunohistochemical staining; (3) All the patients were histological-proven adenocarcinoma and had complete information on immunohistochemistry, including estrogen receptor (ER), progesterone receptor (PR), Her2, P53, and Ki67; (4) All patients were administrated different cycles of planned-dose neoadjuvant according to a multi-agent chemotherapy protocols including TAC (docetaxel/ doxorubicin/ cyclophosphamide), TEC (docetaxel/ epirubicin/ cyclophosphamide), TA (docetaxel/ pirarubicin), TE (docetaxel/ epirubicin), EC (epirubicin/ cyclophosphamide), CEF (cyclophosphamide/ epirubicin/ fluorouracil). (5) All patients were implemented with R0 resection of mastectomy or lumpectomy with either ipsilateral sentinel lymph node biopsy or axillary dissection after evaluating the curative effect of neoadjuvant chemotherapy; (6). Surgical pathology reports were reviewed according to the $7^{\text {th }}$ edition of the AJCC Cancer Staging Manual. Thus, there were 46 patients enrolled in this study. The summary of clinicopathological characteristics were shown in Table 5.

The Ethics Committee of Tianjin Cancer Institute and Hospital approved this research project. Written consents were obtained from each patient.

\section{Immunohistochemistry (IHC) for IDO and IL-6 expression}

Formaldehyde-fixed, paraffin-embedded tissue samples obtained by coarse needle biopsy and mastectomy were sectioned into $4 \mu \mathrm{m}$ slices and affixed on glass slides. The immunohistochemical staining was performed according to the instruction manuals. After being heated for half an hour at $56^{\circ} \mathrm{C}$, the slides were deparaffinized in xylene and rehydrated through graded alcohol. Antigens were retrieved by heating in citrate buffer for 3 minutes and endogenous peroxidase activity was quenched in a bath of methanol and hydrogen peroxide for 30 minutes. The slides were incubated with mouse anti-human IDO monoclonal antibody (Chemicon Corporation, MA, USA) at concentration of 1:300 or mouse anti-human IL-6 monoclonal antibody (Biolegend company, San Diego, CA) at concentration of $1: 200$ at $4{ }^{\circ} \mathrm{C}$ overnight. The antibody were detected by a biotinylated secondary antibody (goat anti-mouse IgG-HRP, sc-2302, Santa Cruz, Cali, USA) labeled with streptavidin-horseradish peroxidase (HRP), a DAB staining kit was used for the visualization of immune reactive cells. IDO antibody IHC of human placenta were positive control, Mouse/rabbit isotype IgG1 were used as the negative controls. Positive cells were stained brownish yellow in the cytoplasm. For semi-quantitative analysis, staining rate (SR) and staining index (SI) both were indicators to describe protein 
expression of IDO and IL-6. The SRs referred to the percentages of positive samples in all samples. IDO and IL-6 expression score was separated from 0 to $3(0=5 \%$ of tumor cells were stained; $1=5-30 \%$ were stained; $2=30$ $70 \%$ were stained; $3=70 \%$ were stained). The SIs was determined upon the average of at least five high-powered fields (400×magnification) and separated from 0 to 3 $(0=$ no staining; $1=$ mild staining; $2=$ moderate staining; $3=$ strong staining). The last score was the sum of two parts above. The low expression was defined the last score $\leq 3$, The high expression was defined the last score $>3$ [37]. All samples were reviewed by experienced pathologists who were blinded to the identity of the specimens. The detailed SR and SI for each case were shown in Supplementary Table 1 .

\section{Double-labeling immunofluorescence method}

To examine the co-localization of IDO and IL-6, a double immunofluorescence study was performed as described previously [22]. The tissue section displayed strong positive expression in immunohistochemistry analysis was selected for the double-labeling immunofluorescence method. Paraffin sections were deparaffinized, microwaved and then incubated with the primary antibodies [mouse anti-human IDO monoclonal antibody (Chemicon Corporation, MA, USA) at concentration of 1:300 or mouse anti-human IL-6 monoclonal antibody (Biolegend company, San Diego, CA) at concentration of 1:200] overnight at room temperature. Then, the sections were incubated with fluorescent secondary antibodies [Alexa 594-labeled goat antibody against mouse IgG and Alexa 488-labeled goat antibody against rabbit IgG (1:400 each, Molecular Probes Inc., Eugene, OR, USA)] for 3 hours at room temperature. The stained sections were examined under a fluorescent microscope (BX53, Olympus, Tokyo, Japan).

\section{ELISA for serum IL-6 level}

Blood was sampled from patients the day before coarse needle biopsy. After 30 min of coagulation, samples were centrifuged in a refrigerated centrifuge at $4^{\circ} \mathrm{C}$ for $10 \mathrm{~min}$ at $2000 \mathrm{rpm}$. Samples were stored in aliquots of $250 \mu \mathrm{L}$ at $-80^{\circ} \mathrm{C}$ until use. We analyzed serum IL-6 using ELISA kits (Genzyme, Cambridge, MA) following the manufacturer's instructions. The optical density (OD) was measured at $450 \mathrm{~nm}(630 \mathrm{~nm}$ as reference) by means of an Organon Teknika Microwell system (Reader 230s, Germany). A standard curve was obtained based on serial dilutions of r-IL-6, ranging from $1 \mathrm{ng} / \mathrm{mL}$ to $250 \mathrm{ng} / \mathrm{mL}$. The results were expressed as concentrations of IL-6 (ng/ $\mathrm{mL}$ ) extrapolated from the standard curve. In view of determining the detection specificity, three positive serum samples were submitted to a neutralization test.

\section{Pathologic evaluation}

The initial core biopsy sample of the primary tumor was evaluated using standard hematoxylin and eosin staining, IHC, and fluorescence or chromogenic in situ hybridization (FISH) (or both) to determine the histological subtype, the Ki67 index, and the status of ER, PR, and Her-2. Cut-off values for ER, PR, and Ki67 were $10 \%, 10 \%$, and $20 \%$, respectively [38]. Her-2 was scored for the intensity and the completeness of cell membrane staining (-, no staining; +, weak partial membranous staining in more than $10 \%$ tumor cells; ++ , moderately complete membrane staining in more than or equal to 10 $\%$ tumor cells or strong complete membranous staining in less than or equal to $10 \%$ of tumor cells; +++ , strong complete membranous staining in more than $10 \%$ of tumor cells). Her-2 (+++) was defined as positive. FISH assay was performed in cases with ++ immunoreactivity [39]. The luminal subtypes were based on IHC of ER, PR and Her-2 [40].

\section{Response to neoadjuvant chemotherapy}

Clinical response was assessed based on a physical examination, mammography, and ultrasonography according to the Response Evaluation Criteria in Solid Tumors (RECIST 1.1). A clinical complete response (CR) was defined as the disappearance of all known lesions; a clinically partial response (PR) was defined as a $\geq 30 \%$ reduction in the sum of the longest diameter of the primary lesion; progressive disease (PD) was defined as a $\geq 20 \%$ increase in the sum of the longest diameter of the primary lesion; and stable disease (SD) was defined as neither sufficient shrinkage to qualify for $\mathrm{cPR}$ nor sufficient increase to qualify for PD [40].

pCR was defined as no evidence of invasive carcinoma in the breast at the time of surgery in line with the criteria of the National Surgical Adjuvant Breast and Bowel Project B-18 [42].

\section{Statistical analyses}

The Chi-square and the Fisher's exact tests were used for categorical variables. Continuous variables presented as $\bar{x} \pm s$, difference between groups were assessed by independent $t$ test. The spearman' rank-order test and liner regression analysis was used to assess correlations between continuous variables, while Pearson's test was used to assess correlations between continuous variables and classification of variables. The Logistic regression was applied in analysis the correlation between clinical features and response of neoadjuvant chemotherapy. The factors that had significant difference in univariate analysis were included in the multivariate logistic regression analysis. The survival curves were 
analyzed via Kaplan-Meier and Log-rank test. A $P$ value $<0.05$ was considered statistically significance. The statistical analysis was performed using SPSS 17.0 software package.

\section{Author contributions}

Fangxuan Li, Juntian Liu and Lijuan Wei analyzed and interpreted the patient data. Fangxuan Li performed the IHC, ELISA and histological examination of the cancer tissues, and Fangxuan Li was a major contributor in writing the manuscript. Shixia Li was analyzed and interpreted and revised the manuscript. All authors read and approved the final manuscript.

\section{CONFLICTS OF INTEREST}

None.

\section{FUNDING}

The work was supported by National Natural Science Fund of China (81502309).

\section{REFERENCES}

1. McGuire A, Brown JA, Malone C, McLaughlin R, Kerin MJ. Effects of age on the detection and management of breast cancer. Cancers (Basel). 2015; 7:908-929.

2. Saini KS, Taylor C, Ramirez AJ, Palmieri C, Gunnarsson U, Schmoll HJ, Dolci SM, Ghenne C, Metzger-Filho O, Skrzypski M, Paesmans M, Ameye L, Piccart-Gebhart MJ, de Azambuja E. Role of the multidisciplinary team in breast cancer management: results from a large international survey involving 39 countries. Ann Oncol. 2012; 23:853-859.

3. Mieog JS, van der Hage JA, van de Velde CJ. Preoperative chemotherapy for women with operable breast cancer. Cochrane Database Syst Rev. 2007; D5002.

4. Kaufmann M, von Minckwitz G, Smith R, Valero V, Gianni L, Eiermann W, Howell A, Costa SD, Beuzeboc P, Untch M, Blohmer JU, Sinn HP, Sittek R, et al. International expert panel on the use of primary (preoperative) systemic treatment of operable breast cancer: review and recommendations. J Clin Oncol. 2003; 21:2600-2608.

5. Tanioka M, Shimizu C, Yonemori K, Yoshimura K, Tamura K, Kouno T, Ando M, Katsumata N, Tsuda H, Kinoshita T, Fujiwara Y. Predictors of recurrence in breast cancer patients with a pathologic complete response after neoadjuvant chemotherapy. Br J Cancer. 2010; 103:297-302.

6. Cortazar P, Geyer CJ. Pathological complete response in neoadjuvant treatment of breast cancer. Ann Surg Oncol. $2015 ; 22: 1441-1446$.

7. Swann JB, Vesely MD, Silva A, Sharkey J, Akira S, Schreiber RD, Smyth MJ. Demonstration of inflammation-induced cancer and cancer immunoediting during primary tumorigenesis. Proc Natl Acad Sci U S A. 2008; 105:652-656.

8. Culig Z, Puhr M. Interleukin-6: a multifunctional targetable cytokine in human prostate cancer. Mol Cell Endocrinol. 2012; 360:52-58.

9. Hagi $T$, Nakamura $T$, Iino $T$, Matsubara $T$, Asanuma $K$, Matsumine A, Sudo A. The diagnostic and prognostic value of interleukin-6 in patients with soft tissue sarcomas. Sci Rep. 2017; 7:9640.

10. Wu CT, Chen MF, Chen WC, Hsieh CC. The role of IL-6 in the radiation response of prostate cancer. Radiat Oncol. 2013; 8:159.

11. Borsellino N, Belldegrun A, Bonavida B. Endogenous interleukin 6 is a resistance factor for cisdiamminedichloroplatinum and etoposide-mediated cytotoxicity of human prostate carcinoma cell lines. Cancer Res. 1995; 55:4633-4639.

12. Gritsko T, Williams A, Turkson J, Kaneko S, Bowman T, Huang M, Nam S, Eweis I, Diaz N, Sullivan D, Yoder S, Enkemann S, Eschrich S, et al. Persistent activation of stat3 signaling induces survivin gene expression and confers resistance to apoptosis in human breast cancer cells. Clin Cancer Res. 2006; 12:11-19.

13. Patel SA, Bhambra U, Charalambous MP, David RM, Edwards RJ, Lightfoot T, Boobis AR, Gooderham NJ. Interleukin-6 mediated upregulation of CYP1B1 and CYP2E1 in colorectal cancer involves DNA methylation, miR27b and STAT3. Br J Cancer. 2014; 111:2287-2296.

14. Muller AJ, DuHadaway JB, Chang MY, Ramalingam A, Sutanto-Ward E, Boulden J, Soler AP, Mandik-Nayak L, Gilmour SK, Prendergast GC. Non-hematopoietic expression of IDO is integrally required for inflammatory tumor promotion. Cancer Immunol Immunother. 2010; 59:1655-1663.

15. Li F, Huang J, Li S, Li H, Yu J, Ren X, Liu J. The subsets of dendritic cells and memory $\mathrm{T}$ cells correspond to indoleamine 2,3-dioxygenase in stomach tumor microenvironment. Tumour Biol. 2014; 35:8691-8698.

16. Muller AJ, DuHadaway JB, Donover PS, Sutanto-Ward E, Prendergast GC. Inhibition of indoleamine 2,3-dioxygenase, an immunoregulatory target of the cancer suppression gene Bin1, potentiates cancer chemotherapy. Nat Med. 2005; 11:312-319.

17. Okamoto A, Nikaido T, Ochiai K, Takakura S, Saito M, Aoki Y, Ishii N, Yanaihara N, Yamada K, Takikawa $\mathrm{O}$, Kawaguchi $\mathrm{R}$, Isonishi $\mathrm{S}$, Tanaka $\mathrm{T}$, Urashima $\mathrm{M}$. Indoleamine 2,3-dioxygenase serves as a marker of poor prognosis in gene expression profiles of serous ovarian cancer cells. Clin Cancer Res. 2005; 11:6030-6039.

18. Li M, Bolduc AR, Hoda MN, Gamble DN, Dolisca SB, Bolduc AK, Hoang K, Ashley C, McCall D, Rojiani AM, Maria BL, Rixe O, MacDonald TJ, et al. The indoleamine 2,3-dioxygenase pathway controls complement-dependent 
enhancement of chemo-radiation therapy against murine glioblastoma. J Immunother Cancer. 2014; 2:21.

19. Uyttenhove C, Pilotte L, Theate I, Stroobant V, Colau D, Parmentier N, Boon T, Van den Eynde BJ. Evidence for a tumoral immune resistance mechanism based on tryptophan degradation by indoleamine 2,3-dioxygenase. Nat Med. 2003; 9:1269-1274.

20. Kim H, Chen L, Lim G, Sung B, Wang S, McCabe MF, Rusanescu G, Yang L, Tian Y, Mao J. Brain indoleamine 2,3-dioxygenase contributes to the comorbidity of pain and depression. J Clin Invest. 2012; 122:2940-2954.

21. Litzenburger UM, Opitz CA, Sahm F, Rauschenbach KJ, Trump S, Winter M, Ott M, Ochs K, Lutz C, Liu X, Anastasov N, Lehmann I, Höfer T, et al. Constitutive IDO expression in human cancer is sustained by an autocrine signaling loop involving IL-6, STAT3 and the AHR. Oncotarget. 2014; 5:1038-1051. https://doi.org/10.18632/ oncotarget. 1637.

22. Soliman H, Rawal B, Fulp J, Lee JH, Lopez A, Bui MM, Khalil F, Antonia S, Yfantis HG, Lee DH, Dorsey TH, Ambs S. Analysis of indoleamine 2-3 dioxygenase (IDO1) expression in breast cancer tissue by immunohistochemistry. Cancer Immunol Immunother. 2013; 62:829-837.

23. Sim SH, Ahn YO, Yoon J, Kim TM, Lee SH, Kim DW, Heo DS. Influence of chemotherapy on nitric oxide synthase, indole-amine-2,3-dioxygenase and CD124 expression in granulocytes and monocytes of non-small cell lung cancer. Cancer Sci. 2012; 103:155-160.

24. Inaba $\mathrm{T}$, Ino $\mathrm{K}$, Kajiyama $\mathrm{H}$, Yamamoto $\mathrm{E}$, Shibata $\mathrm{K}$, Nawa A, Nagasaka T, Akimoto H, Takikawa O, Kikkawa F. Role of the immunosuppressive enzyme indoleamine 2,3-dioxygenase in the progression of ovarian carcinoma. Gynecol Oncol. 2009; 115:185-192.

25. Salvadori ML, Da CBP, Gebrim LH, Silva RS, Kfoury JJ. Effect of the association of 1-methyl-DL-tryptophan with paclitaxel on the expression of indoleamine 2,3-dioxygenase in cultured cancer cells from patients with breast cancer. Med Oncol. 2015; 32:248.

26. Nakanishi C, Toi M. Nuclear factor-kappaB inhibitors as sensitizers to anticancer drugs. Nat Rev Cancer. 2005; 5:297-309.

27. Shibayama O, Yoshiuchi K, Inagaki M, Matsuoka Y, Yoshikawa E, Sugawara Y, Akechi T, Wada N, Imoto S, Murakami K, Ogawa A, Akabayashi A, Uchitomi Y. Association between adjuvant regional radiotherapy and cognitive function in breast cancer patients treated with conservation therapy. Cancer Med. 2014; 3:702-709.

28. Chen F, Zhuang X, Lin L, Yu P, Wang Y, Shi Y, Hu G, Sun Y. New horizons in tumor microenvironment biology: challenges and opportunities. BMC Med. 2015; 13:45.

29. Hara M, Nagasaki T, Shiga K, Takahashi H, Takeyama H. High serum levels of interleukin-6 in patients with advanced or metastatic colorectal cancer: the effect on the outcome and the response to chemotherapy plus bevacizumab. Surg Today. 2017; 47:483-489.

30. Ignatoski KM, Friedman J, Escara-Wilke J, Zhang X, Daignault S, Dunn RL, Smith DC, Keller ET. Change in markers of bone metabolism with chemotherapy for advanced prostate cancer: interleukin- 6 response is a potential early indicator of response to therapy. J Interferon Cytokine Res. 2009; 29:105-112.

31. Conze D, Weiss L, Regen PS, Bhushan A, Weaver D, Johnson P, Rincon M. Autocrine production of interleukin 6 causes multidrug resistance in breast cancer cells. Cancer Res. 2001; 61:8851-8858.

32. Gupta PB, Fillmore CM, Jiang G, Shapira SD, Tao K, Kuperwasser C, Lander ES. Stochastic state transitions give rise to phenotypic equilibrium in populations of cancer cells. Cell. 2011; 146:633-644.

33. Smith C, Chang MY, Parker KH, Beury DW, DuHadaway JB, Flick HE, Boulden J, Sutanto-Ward E, Soler AP, Laury-Kleintop LD, Mandik-Nayak L, Metz R, OstrandRosenberg S, et al. IDO is a nodal pathogenic driver of lung cancer and metastasis development. Cancer Discov. 2012; 2:722-735.

34. Hofer T, Nathansen H, Lohning M, Radbruch A, Heinrich R. GATA-3 transcriptional imprinting in Th2 lymphocytes: a mathematical model. Proc Natl Acad Sci U S A. 2002; 99:9364-9368.

35. Li F, Zhang R, Li S, Liu J. IDO1: An important immunotherapy target in cancer treatment. Int Immunopharmacol. 2017; 47:70-77.

36. McShane LM, Altman DG, Sauerbrei W, Taube SE, Gion M, Clark GM. Reporting recommendations for tumor marker prognostic studies (REMARK). J Natl Cancer Inst. 2005; 97:1180-1184.

37. Boltze C, Riecke A, Ruf CG, Port M, Nizze H, Kugler C, Miethke C, Wiest N, Abend M. Sporadic and radiationassociated papillary thyroid cancers can be distinguished using routine immunohistochemistry. Oncol Rep. 2009; 22:459-467.

38. Ignatiadis M, Buyse M, Sotiriou C. St Gallen International Expert Consensus on the primary therapy of early breast cancer: an invaluable tool for physicians and scientists. Ann Oncol. 2015; 26:1519-1520.

39. Bianchi S, Caini S, Paglierani M, Saieva C, Vezzosi V, Baroni G, Simoni A, Palli D. Accuracy and reproducibility of HER2 status in breast cancer using immunohistochemistry: a quality control study in Tuscany evaluating the impact of updated 2013 ASCO/CAP recommendations. Pathol Oncol Res. 2015; 21:477-485.

40. Sim SH, Bae CD, Kwon Y, Hwang HL, Poojan S, Hong HI, Kim K, Kang SH, Kim HS, Um TH, Park IH, Lee KS, Jung SY, et al. CKAP2 (cytoskeleton-associated protein2) is a new prognostic marker in HER2-negative luminal type breast cancer. PLoS One. 2017; 12:e182107. 
41. Eisenhauer EA, Therasse P, Bogaerts J, Schwartz LH, Sargent D, Ford R, Dancey J, Arbuck S, Gwyther S, Mooney M, Rubinstein L, Shankar L, Dodd L, et al. New response evaluation criteria in solid tumours: revised RECIST guideline (version 1.1). Eur J Cancer. 2009; 45:228-247.
42. Wolmark N, Wang J, Mamounas E, Bryant J, Fisher B. Preoperative chemotherapy in patients with operable breast cancer: nine-year results from National Surgical Adjuvant Breast and Bowel Project B-18. J Natl Cancer Inst Monogr. 2001; 96-102. 